\title{
Sexual dysfunction during primiparous and multiparous women following vaginal delivery
}

MEHRI MAKKI ${ }^{1}$ and NOOSHIN ABDOLI YAZDI ${ }^{2}$

${ }^{1}$ Faculty of Midwifery, Maybod Branch, Islamic Azad University, Maybod, Iran

${ }^{2}$ Varamin Branch, Islamic Azad University, Varamin, Iran

\begin{abstract}
Normal sexual functioning comprises of sexual activity together with transition through the phases from arousal to relaxation with no problem. Delivery has different effects on body organs, especially, on genitalia the disorder of which can cause sexual dysfunctions. In this study, an attempt is made to compare postpartum sexual dysfunction among primiparous and multiparous women. This descriptive cross sectional study was done on 564 primiparous (331) and multiparous (233) women chosen from among those who were present at health and clinical centres in Yazd, Iran. Data were gathered through a questionnaire consisting of demographics and questions related to sexual problems before and after 3-6 months of delivery. Both open-ended and closed items were included in the questionnaire. The questionnaire was developed in consultation with two health educators, a midwife, two gynaecologists and an expert in questionnaire validation. All registered data were analyzed by SPSS15 software. Dyspareunia was shown to decrease after pregnancy in both primigravidae and multigravidae women $(P<0.05)$. Libido decreased during multigravidae $(P<0.05)$ while the difference was not significant during primigravidaes $(P>0.05)$. Also, vaginal loosening was significantly increased in multigravid women $(P<0.05)$ while it did not significantly change in primigravidae $(P>0.05)$. The difference was not significant in primigravidae nor in multigravidae according to post coital bleeding, post coital itching, an-orgasmia, oral sex and anal sex. In conclusion, based on the results of this study, delivery has limited effects on sexual function of primiparous and multiparous women. Contradictory results of similar studies show the need for a precise critical appraisal and finding pitfalls of previous studies. Designing more valid surveys with larger sample size to determine the effects of delivery and parity on sexual function is recommended.
\end{abstract}

Keywords: sexual dysfunction, women, delivery, Iran

\section{Introduction}

Normal sexual functioning comprises of sexual activity together with transition through the phases from arousal to relaxation with no problems, and with a feeling of pleasure, fulfilment, and satisfaction (Baessler \& Schuessler, 2003). Delivery has different effects on body organs especially on genitalia, the disorder of which can cause sexual dysfunctions (Gorrie, 1998). Sexual dysfunction or sexual malfunction refers to a difficulty experienced by an individual or a couple during any stage of a normal sexual activity, including desire, arousal or orgasm (Basson et al., 2003). After delivery, ordinary women get involved in problems like painful intercourses, decreased libido, vaginal dryness and failure to reach orgasm. These problems can be long lasting and make problems in marital relationships (Barrette et al., 2000). Estimations shows that about $20 \%$ of women have painful intercourses (dyspareunia) during first three months after delivery (Henderson \& Kathleen, 1997) and at least 10\% experience perineal pain during intercourse (Glazener et al., 1995).

It has been reported that six months from delivery, one in five women report dyspareunia (Robson et al., 1981; Klein et al., 1994; Glazener, 1997) and up to one in nine may 
not have resumed sexual activity (Barrette et al., 2000). Libido decreases during pregnancy until months after delivery (Forster, 1994). Surveys show that the frequency of intercourses lowers the contrast before pregnancy and the mode of delivery is related to sexual dysfunction of women after delivery (Forster, 1994). Of course painful intercourse and other sexual disorders are more prevalent among women with vaginal delivery (Forster, 1994).

Some other studies showed that sexual disorders are more prevalent in women whose delivery was done through helping forceps or vacuum.

Painful intercourse is more frequent in women with grades three or four vaginal tearing contrasting with those of grade two tearing or with episiotomy (Sleep \& Grant, 1987). Also, the mode of delivery, perineal injuries and history of dyspareunia before pregnancy are related to post delivery sexual dysfunctions. In a study that surveyed on sexual dysfunctions of primiparous women before and after delivery, authors concluded that vaginal dryness, post coital bleeding, post coital itching and loose vagina were seen more before than after delivery (Barrette et al., 2000).

At postpartum period, changes in sexual relationship between couples can cause problems in marital relationships. To some extent it causes dissatisfaction of sexual intercourse (Bispham, 1997), sense of fatigue and even depression (Glazener, 1997). Sexual unhappiness is one of the most important problems that couples deny because of shame; even if they feel a need for further consultation about it (Barrette et al., 2000; Melissa \& Frantzich, 2000) and this real need of couples is usually forgotten by health staffs. Considering the effect of sexual dysfunction on interpersonal relationship of couples and the duty of health care systems to defend the psychological health of community, detecting factors that have influence on sexual dysfunction is necessary for designing effective and functional educational programmes. There are several studies on effect of mode of delivery or comparison of nulliparity with multiparity in the context of sexual dysfunctions, but there are clearly few studies on comparison of primiparity with multiparity. Hence, this study tried to compare postpartum sexual dysfunction in primiparous and multiparous women.

\section{Materials and Methods}

\section{Study site and population}

This cross sectional case control study was done from June 2011 to February 2012 in health and clinical centres of Yazd in Iran. Sample size was calculated by pilot study. After piloting 100 women, prevalence of sexual disorders after delivery was detected as 52\%; and based on $95 \%$ of confidence interval, study power of $90 \%, 400$ patients were needed for the study (200 patients for each group). The patients who participated in pilot study were not included in the main study. All primiparous and multiparous (up to five children) women who were present in Yazd health and clinical centres and had term pregnancy at the time of delivery, and a period of 3-6 months had passed from their delivery were included in the study.

Sampling was carried out through contentious sampling, considering the exact date of delivery. The subjects were selected in a manner to have enough and equal numbers of cases who had passed 3, 4, 5 and six months of delivery. Women attending health and clinical centres 
of Yazd City were interviewed and those matched with inclusion criteria were selected for study after taking consent. This process was continued until the required sample size was reached.

Exclusion criteria consisted of the following situations: known underlying diseases (such as heart or pulmonary diseases) that affect on sexual function; any drugs which have effects on sexual function (e.g. anti-depressants, anti hypertensives), being far from husband because of any reasons; post-partum blue; delivery with grades three or four laceration or extensive episiotomy; infertility (male or female) or history of abortion.

\section{Data collection}

During consecutive days and weeks, researchers attended the health and clinical centres and after communication with the women, identified the eligible cases for the study and after taking consent for participation in the study, gave them the questionnaire to be filled up. This process took about three months. Data were collected through a questionnaire consisting of demographics and questions related to sexual problems before and after 3-6 months of delivery. Both open-ended and closed questions were included in the questionnaire. Questions about the sexual relationships were closed with Yes or No answers. There were no follow ups and data were gathered at one section only. The questionnaire was developed in consultation with two health educators, a midwife, two gynaecologists and an expert in questionnaire validation. The validity of the questionnaire was assessed by a healthcare specialist, with its reliability being determined by piloting and measuring the related Cronbach Alpha value (Alpha=0.760). All registered data were entered into SPSS-15 software and analyzed through MacNemar test.

\section{Ethical considerations}

The study received approval from Ethics Committee of the Islamic Azad University in Maybod, Iran. All study subjects provided a written informed consent.

\section{Results}

A total of 564 participants were included in the analysis (331 in primiparous and 233 in multiparous groups). Mean age of participants was $20.25 \pm 4.37$ in primiparous group and $22.56 \pm 4.79$ years in multiparous group. Thirty three $(5.44 \%)$ of all participants were illiterate, $160(26.4 \%)$ had primary school education, $87(14.35 \%)$ had guidance school education, 162 (26.7\%) had high school education and 164 (27.06\%) had academic degrees. A total of 105 primigravid participants had pain during intercourse (dyspareunia) before pregnancy, while the frequency of this problem decreased to 59 ( $P=0.001$; MacNemar). In multigravid women, 70 patients had pain during intercourse the frequency of which decreased to 44 after the second delivery $(P=0.002)$ (Table 1$)$. Post coital bleeding was seen in 18 primigravid and 13 women which increased to 20 in primigravid $(P=0.82)$ and decreased to 11 in multigravid women $(\mathrm{P}=0.80)$ (Table1). Also post coital itching did not significantly change before and after delivery neither in primigravid nor in multigravid women (Table1). 
Loose vagina was observed in 34 primigravid women before pregnancy, while after delivery it was detected in 37 patients $(P=0.50)$. But among multigravid women, the frequency of loose vagina increased from 24 participants to $46(P=0.001)$ (Table 1). Vaginal dryness did not significantly change in primigravid or multigravid women before and after delivery (Table1).

Low sex drive (libido) was reported in 98 primigravid women before pregnancy and 89 after delivery $(P=0.302)$. Low sex drive was observed in 80 and 99 multigravid women before and after pregnancy and delivery respectively $(P=0.004$ (Table 2). An-orgasmia, oral and anal sex did not change in rate neither primigravidaes nor in multigravides before pregnancy and after delivery (Table 2).

Table 1: Frequency of dyspareunia, post coital bleeding, post coital itching, vaginal loosening and vaginal dryness in groups of study

\begin{tabular}{|c|c|c|c|c|c|c|}
\hline \multirow[t]{2}{*}{ Variable } & \multirow[t]{2}{*}{ Parity } & \multirow{2}{*}{$\begin{array}{l}\text { Response } \\
\text { Before } \\
\text { pregnancy }\end{array}$} & \multicolumn{2}{|c|}{ After delivery } & \multirow[t]{2}{*}{ Total } & \multirow[t]{2}{*}{ P-value } \\
\hline & & & No & Yes & & \\
\hline \multirow[t]{6}{*}{ Dyspareunia } & Primiparous & No & 207 & 19 & 226 & \\
\hline & & Yes & 65 & 40 & 105 & 0.001 \\
\hline & & Total & 272 & 59 & 331 & \\
\hline & Multiparous & No & 142 & 21 & 163 & \\
\hline & & Yes & 47 & 23 & 70 & 0.002 \\
\hline & & Total & 189 & 44 & 233 & \\
\hline \multirow{6}{*}{$\begin{array}{l}\text { Post-coital } \\
\text { bleeding }\end{array}$} & Primiparous & No & 301 & 11 & 312 & 0.824 \\
\hline & & Yes & 9 & 9 & 18 & \\
\hline & & Total & 310 & 20 & 330 & \\
\hline & Multiparous & No & 211 & 7 & 218 & 0.804 \\
\hline & & Yes & 9 & 4 & 13 & \\
\hline & & Total & 220 & 11 & 231 & \\
\hline \multirow{6}{*}{$\begin{array}{l}\text { Post-coital } \\
\text { itching }\end{array}$} & Primiparous & No & 253 & 16 & 269 & \\
\hline & & Yes & 17 & 43 & 60 & 1.00 \\
\hline & & Total & 270 & 59 & 329 & \\
\hline & Multiparous & No & 164 & 22 & 186 & 0.417 \\
\hline & & Yes & 16 & 28 & 44 & \\
\hline & & Total & 180 & 50 & 230 & \\
\hline \multirow{6}{*}{$\begin{array}{l}\text { Vaginal } \\
\text { loosening }\end{array}$} & Primiparous & No & 288 & 6 & 294 & \\
\hline & & Yes & 3 & 31 & 34 & 0.508 \\
\hline & & Total & 291 & 37 & 328 & \\
\hline & Multiparous & No & 183 & 22 & 205 & 0.001 \\
\hline & & Yes & 0 & 24 & 24 & \\
\hline & & Total & 183 & 46 & 229 & \\
\hline \multirow{6}{*}{$\begin{array}{l}\text { Vaginal } \\
\text { dryness }\end{array}$} & Primiparous & No & 280 & 11 & 291 & \\
\hline & & Yes & 12 & 24 & 36 & 1.00 \\
\hline & & Total & 292 & 35 & 327 & \\
\hline & Multiparous & No & 186 & 15 & 201 & 0.424 \\
\hline & & Yes & 10 & 19 & 29 & \\
\hline & & Total & 196 & 34 & 230 & \\
\hline
\end{tabular}


Table 2: Frequency of lack of libido, an-orgasmia, oral sex and anal sex in groups of study

\begin{tabular}{|c|c|c|c|c|c|c|}
\hline \multirow[t]{2}{*}{ Variable } & \multirow[t]{2}{*}{ Parity } & \multirow{2}{*}{$\begin{array}{l}\text { Response } \\
\text { Before } \\
\text { pregnancy } \\
\end{array}$} & \multicolumn{2}{|c|}{ After delivery } & \multirow[t]{2}{*}{ Total } & \multirow[t]{2}{*}{ P-value } \\
\hline & & & No & Yes & & \\
\hline \multirow[t]{6}{*}{ Lack of libido } & Primiparous & No & 205 & 27 & 232 & \\
\hline & & Yes & 19 & 79 & 98 & 0.302 \\
\hline & & Total & 224 & 106 & 330 & \\
\hline & Multiparous & No & 123 & 29 & 152 & 0.004 \\
\hline & & Yes & 10 & 70 & 80 & \\
\hline & & Total & 133 & 99 & 232 & \\
\hline \multirow[t]{6}{*}{ An-orgasmia } & Primiparous & No & 174 & 17 & 191 & 0.584 \\
\hline & & Yes & 13 & 125 & 138 & \\
\hline & & Total & 187 & 142 & 329 & \\
\hline & Multiparous & No & 113 & 17 & 130 & 0.17 \\
\hline & & Yes & 9 & 92 & 101 & \\
\hline & & Total & 122 & 109 & 231 & \\
\hline \multirow[t]{6}{*}{ Anal sex } & Primiparous & No & 304 & 3 & 307 & 0.508 \\
\hline & & Yes & 6 & 13 & 19 & \\
\hline & & Total & 310 & 16 & 326 & \\
\hline & Multiparous & No & 213 & 4 & 217 & 1.00 \\
\hline & & Yes & 4 & 10 & 14 & \\
\hline & & Total & 217 & 14 & 231 & \\
\hline \multirow[t]{6}{*}{ Oral sex } & Primiparous & No & 295 & 9 & 304 & 0.424 \\
\hline & & Yes & 5 & 14 & 19 & \\
\hline & & Total & 300 & 23 & 323 & \\
\hline & Multiparous & No & 211 & 8 & 219 & 0.23 \\
\hline & & Yes & 4 & 7 & 11 & \\
\hline & & Total & 215 & 15 & 230 & \\
\hline
\end{tabular}

\section{Discussion}

Normal sexual functioning comprises of sexual activity together with transition through the phases from arousal to relaxation with no problems. Ordinary women after delivery get involved in problems like painful intercourse, decreased libido, vaginal dryness and failure to reach orgasm. These problems can be long lasting and cause problems in marital relationships (Barrette et al., 2000; Baessler \& Schuessler, 2003). Based on our study dyspareunia was shown to decrease after pregnancy in both primigravid and multigravid women. Libido decreased during multigravid while the difference was not significant during primigravid. Also, vaginal loosening was significantly increased in multigravid women while it did not significantly change in primigravids. The difference was not significant in primigravidaes nor in multigravides according to post coital bleeding, posts coital itching, an-orgasmia, oral sex and anal sex.

In a recent study on sexual problems among 160 primiparous women, painful penetration, dyspareunia, itching after intercourse, lack of vaginal lubrication, loss of sexual 
desire, difficulty in reaching orgasm and anal sexual relation increased after delivery (Nikpour et al., 2006). The present study only reported significant difference in dyspareunia which decreased after delivery. In another study by Asadzadeh et al. (2011), results showed that sexual problems were higher in women with normal vaginal delivery than with caesarean and also were higher in patients with normal vaginal delivery before pregnancy than after delivery (Bolurian et al., 2007). Similar results have been reported from a study by Safarinejad et al. (2009). In contrary, Klein et al. (2009 found that there was no significant difference in sexual function 12-18 months after childbirth between women who delivered vaginally without episiotomy, heavy perineal laceration, or secondary operative interventions and women who underwent elective caesarean section.

In a study in Mexico (Solana-Arellano et al., 2008) involving 304 women during 60-180 days after child birth, dyspareunia was related to complications with episiotomy and its possible sequelae, such as infection, episiorrhaphy dehiscence, and constricted introitus. However, the results of our current study did not support such difference. The participants of the study in Mexico had passed a period of 60-180 days after delivery, while the participants of this study had spent 3-6 months period after childbirth. In fact our study population had passed at least three months of delivery while some of patients in the Mexico study passed only two months from child birth. It is possible that effect of episiotomy scar be remained during third month after delivery and the effect of these patients' responses affected on the results of that study.

Findings of a study by Witting et al. (2008) showed that multiparous women had less orgasm problems compared to nulliparous women. Nulliparous women had more pain problems and were sexually less satisfied compared to women with children, regardless the number. These results are also different from the results of present research, because no significant difference was found in orgasm. Although a significant lower libido was found among multiparous there was no difference among nulliparous women.

Barrett et al. (2000) investigated the impact of childbirth on the sexual health among primiparous women by a cross sectional study. Results showed that during the first three months after delivery, $83 \%$ of the participants experienced sexual problems compared to $38 \%$ who experienced the problems before pregnancy. Dyspareunia was also higher in patients with vaginal delivery. However, after six months, the association between mode of delivery and sexual disorders was not significant (Barrett et al., 2000). These results are not concomitant with our results.

As observed, the results of different studies are inconsistent. These contradictory results can be due to several factors like sampling, weakness of exclusion criteria, weakness of self report questionnaires because of potentially increased recall bias, having no right conception to discriminate between different sexual complaints that can make another confounding bias and also difference in the situation of delivery in several patients. Most of these articles did not introduce any classification of the patients' severity of delivery. This is also due to the study method as most of these studies were retrospective and there were no such information in hospital documents. In conclusion, based on our study delivery has limited effects on sexual function among primiparous and multiparous women. Designing more valid surveys with 
larger sample size to determine the effects of delivery and parity on sexual function is recommended.

\section{Conflict of interest}

Not declared

\section{Acknowledgements}

This study received financial support from Islamic Azad University, Meybod Branch. The authors would like to thank all women who participated in this study for their patience and trust.

\section{References}

Asadzadeh, F., Mashoufi, M., Homayounfar, N., Imanpour, M., Azimi, S., Soltani, R. (2011) Comparison between satisfaction on sexual relationship after normal vaginal delivery (NVD) and caesarean. Iranian Journal of Health $\mathcal{E}$ Care 13, 41-46.

Baessler, K. \& Schuessler, B. (2003) Childbirth-induced trauma to the urethral continence mechanism: Review and recommendations. Urology 62, 39-44.

Barrett, G., Pendry, E., Peacock, J., Victor, C., Thakar, R. \& Manyonda, I. (2000) Women's sexual health after childbirth. BJOG 107, 186-195.

Bispham, A. (1997) Sex after babies. Family Medicine Journal 1, 25-27.

Basson, R., Leiblum, S., Brotto, L., Derogatis, L., Fourcroy, J., Fugl-Meyer, K., Graziottin, A., Heiman, J.R., Laan, E., Meston, C., Schover, L., van Lankveld, J. \& Schultz, W.W. (2003) Definitions of women's sexual dysfunction reconsidered: advocating expansion ad revision. Journal of Psychosomatic Obstetrics \& Gynecology 24, 221-229.

Bolurian, Z., Rakhshani, Z., Rakhshani, M.H. (2007) Pregnancy, gender and its relationship with quality of sexual relations. Iranian Journal of Obstetrics, Gynecology and Infertility 9, 79-84.

Forster, C. (1994) Psychological and sexual changes after the cessation of breast-feeding. Obstetrics \& Gynecology 84, 872-76.

Glazener, C. (1997) Sexual function after childbirth: women's experiences, persistent morbidity and lack of professional recognition. British Journal of Obstetrics and Gynaecology 104, 330-335.

Glazener, C.M., Abdalla, M., Stroud, P., Naji, S., Templeton, A. \& Russell, I.T. (1995) Postnatal maternal morbidity, extent: causes, prevention and treatment. BJOG 102, 282-287.

Gorrie, M. (1998) Foundations of Maternal Newborn Nursing, $2^{\text {nd }}$ ed. Philadelphia: W.B. Saunders Co, 269.

Henderson, C. \& Kathleen, J. (1997) Essential Midwifery, 2nd ed. London, Mosby Ltd, 300.

Klein, M., Gauthier, R., Jorgensen, S., Robbins, J., Kaczorowski, J., Franco, E.D. (1994) Relationship of episiotomy to perineal trauma and morbidity, sexual dysfunction, and pelvic floor relaxation. American Journal of Obstetrics $\mathcal{E}$ Gynecology 171, 591-598. 
Klein, K., Worda, C., Leipold, H., Gruber, C., Husslein, P., Wenzl, R. (2009) Does the mode of delivery influence sexual function after childbirth? Journal of Women Health (Larchmt)18, 1227-1231.

Melissa, D. \& Frantzich, R. (2000) The experience of sexuality during breast feeding among primiparous woman. Journal of Midwifery $\mathcal{E}$ Women's Health, 45, 227-237.

Nikpour, S., Javaheri, I., Yadavar Nikravesh, M. \& Jamshidi, R. (2006) Study of Sexual Problems Resulting from Delivery in Primiparous Women Referred to Outpatient Clinics in West of Tehran. Razi Journal of Medical Sciences 13, 189-196

Robson, K., Brant, H. \& Kumar, R. (1981) Maternal sexuality during first pregnancy and after childbirth. British Journal of Obstetrics and Gynaecology 88, 882-89.

Safarinejad, M.R., Kolahi, A.A. \& Hosseini, L. (2009) The effect of the mode of delivery on the quality of life, sexual function, and sexual satisfaction in primiparous women and their husbands. Journal of Sexual Medicine 6, 1645-1667.

Sleep, J. \& Grant, A. (1987) West Berkshire perineal management trial: three year follow up. BMJ 1295, 749-751.

Solana-Arellano, E., Villegas-Arrizón, A., Legorreta-Soberanis, J., Cárdenas-Turanzas, M., Enzaldo de la Cruz, J. \& Andersson, N. (2008) Women's dyspareunia after childbirth: a case study in a hospital in Acapulco, Mexico. Revisita Panamericana de Salud Pública 23, 44-51

Witting, K., Santtila, P., Alanko, K., Harlaar, N., Jern, P., Johansson, A., Von Der Pahlen, B., Varjonen, M., Algars, M. \& Sandnabba, N.K. (2008) Female sexual function and its associated with number of children, pregnancy, and relationship satisfaction. Journal of Sex and Marital Therapy 34, 89-106. 